\title{
INCÊNDIOS EM VEGETAÇÃO EM CONJUNTO COM OUTROS MATERIAIS COMBUSTIIVEIS NA INTERFACE URBANO-RURAL DE CURITIBA-PR
}

\section{VEGETATION FIRES WITH OTHER COMBUSTIBLE MATERIALS IN CURITIBA WILDLAND- URBAN INTERFACE}

\author{
Heitor Renan Ferreira ${ }^{1}$, Antonio Carlos Batista ${ }^{1}$, Alexandre França Tetto ${ }^{1}$, \\ Bruna Kovalsyki ${ }^{1}$, João Francisco Labres dos Santos ${ }^{1}$ \\ ${ }^{1}$ Universidade Federal do Paraná, Curitiba, Paraná, Brasil - bmheitorf@gmail.com, \\ batistaufpr@gmail.com, tetto@ufpr.br,kovalsyki.b@gmail.com\&joflabres@yahoo.com.br
}

RESUMO

\begin{abstract}
Os incêndios em vegetação são responsáveis por significativas alterações socioeconômicas e ambientais, tanto de aspectos positivos quanto negativos. $O$ aumento da urbanização reduz a distância entre as áreas urbanizadas e as áreas rurais, fazendo com que os seres vivos tenham que se adaptar à interface urbano-rural, caracterizada por aglomerados de edificações em contato aos espaços rurais. O objetivo deste trabalho foi avaliar as ocorrências de incêndio em vegetação misturada com outros materiais combustíveis, para verificar a influência antrópica neste tipo de incêndio. Para isso, foram utilizados os dados das ocorrências atendidas pelo Corpo de Bombeiros da Polícia Militar do Paraná, no município de Curitiba, no período de 2011 a 2015, que foram distribuídos em um mapa de monitoramento de cobertura e uso da terra do Brasil de 2016. Ao todo foram analisadas 1.255 ocorrências de incêndio em vegetação, sendo que 108 destas eram resultantes da queima de combustível vegetal misturado com outros materiais combustíveis caraterísticos de área urbana. Observou-se que houve um aumento crescente do número destas ocorrências no período analisado. Ao comparar as ocorrências com o mapa de cobertura do solo, verificou-se que $94,8 \%$ dos casos foram classificados como "área artificial", que apresenta nível de antropização superior às demais. Conclui-se que houve um aumento do número de ocorrências de incêndio em vegetação misturada com outros tipos de materiais combustíveis e que este tipo de incêndio possui relação causal antrópica, sendo necessário um maior aprofundamento e pesquisas junto à população acerca da utilização do fogo.
\end{abstract}

PALAVRAS-CHAVE: Causa de incêndios, Incêndio florestal, Ocorrências de incêndios.

\section{ABSTRACT}

Vegetation fires are responsible for significant socioeconomic and environmental changes, both positive and negative aspects. Increased urbanization leads to a reduction in the distance between urbanized and rural areas, making living beings have to adapt to the wildland-urban interface, characterized by buildings clusters in contact with rural spaces. The objective of this work was to evaluate the occurrence of fire in vegetation mixed with other combustible materials, in order to verify the anthropic influence in this type of fire. For that, the data of the events served by the Corpo de Bombeiros da Polícia Militar do Paraná, in the municipality of Curitiba, during the period from 2011 to 2015, were used, which were distributed in a monitoring map of land cover and land use in Brazil, 2016. A total of 1,255 fire occurrences in vegetation were analyzed, of which 108 were caused by the burning of vegetable fuel mixed with other combustible materials characteristic of urban areas. It was observed that there was an increasing increase in the number of these occurrences in the analyzed period. When comparing the occurrences with the land cover map, it was verified that $94.8 \%$ of the cases were classified as "artificial area", which presents anthropization level superior to the others. The conclusion is that there was an increase in the number of occurrences of fire in mixed vegetation with other types of combustible materials and that this type of fire has anthropic causal relation, being necessary a further deepening and research with the population about the use of fire.

KEYWORDS: Cause of fire, Forest fire, Fires occurrences. 


\section{INTRODUÇÃO}

Os incêndios naturais, influenciaram a evolução biológica e os ciclos biogeoquímicos globais, tornando o fogo parte integrante no funcionamento de alguns biomas, porém os seres humanos têm a capacidade de alterar os regimes de fogo, de modo a causar degradação dos serviços ecossistêmicos, perturbações econômicas, devido à destruição da infraestrutura, perda de vidas e danos à saúde (BOWMAN et al., 2011). As variações no regime de fogo estão fortemente relacionadas a variabilidade na densidade populacional humana e nos padrões resultantes das atividades de uso da terra e gestão de recursos naturais (LIU \& WIMBERLY, 2015).

Até meados do século 20 a distinção entre floresta, fazenda e cidade era geralmente bem definida (CHANDLER, 1983), porém cada vez mais o avanço dos centros urbanos e o aumento populacional tem miscigenado estas diferentes paisagens, criando uma interface urbano-rural (VÉLEZ, 2009). Conforme Prudente (2014), no Brasil a interface urbano-rural ainda não teve um lugar apropriado no planejamento territorial, por não serem explicitas as distinções entre o urbano e o rural.

Segundo Rosas (2014), a questão ambiental das interfaces urbano-rural no Brasil destaca-se a partir da década de 1990, podendo citar temas como a geração e disposição de lixo, a silvicultura, as áreas de ocupação irregular, uso da água na irrigação e a questão dos agrotóxicos, assoreamento e eutrofização de rios e o desmatamento.

O fogo é utilizado há mais de 500.000 anos para diversas atividades (SOARES et al., 2017), sendo uma importante ferramenta de manejo para os moradores do meio rural, tanto para limpeza e preparo do terreno, estimulo do crescimento de gramíneas forrageiras para o manejo do pasto, redução da incidência de pragas e doenças (ASSUNÇÃO et al., 2017), como para a eliminação de materiais diversos através do processo de combustão, por ser uma alternativa de fácil aplicação e culturalmente empregada para eliminação de resíduos (VÉLEZ, 2009).

Molina et al. (2009) destacam que as pessoas são um dos principais agentes causadores dos incêndios. Vélez (2009) cita que as negligências provocadas pelo pouco cuidado na utilização do fogo contribui para o aumento dos números de incêndios. Ainda, segundo o mesmo autor, a queima de resíduos urbanos (lixos industriais e residenciais) geram um conflito na interface urbano-rural, visto que há um considerável aumento na quantidade de dejetos originados das concentrações urbanas. A falta de controle na manipulação do fogo nestes dejetos pode se tornar um incêndio em vegetação.

Para diminuição dos incêndios em vegetação é necessária uma política preventiva visando sensibilizar a população através de informações sobre o perigo do fogo, conciliando os interesses via uma legislação e política florestal para eliminação dos problemas relacionados os incêndios, bem como punição aos infratores das legislações locais que regulamentam o uso do fogo (VÉLEZ, 2009).

O Corpo de Bombeiros da Polícia Militar do Paraná é o órgão responsável pela execução de atividades de defesa civil, prevenção e combate a incêndios no estado do Paraná, entretanto, a perícia criminalística fica a cargo da Polícia Científica (PARANÁ, 1989), assim, no atendimento das ocorrências, não é verificado a causa do incêndio pelo bombeiro militar. Porém, conforme Heikkilä et al. (2007), essa informação é importante para compreensão de como e por que ocorrem os incêndios em vegetação.

No Brasil são poucas pesquisas que tratam das causas dos incêndios em vegetação devido à dificuldade de obtenção dessas informações. Para a investigação dos incêndios há necessidade de investimento de recursos e tempo, e geralmente as pesquisas são baseadas em uma percepção das pessoas, mediante formulários de registros e aplicação de questionários (SOARES et al., 2017).

Testou-se a hipótese de que as ocorrências de incêndios em vegetação na cidade de Curitiba possuem influência antrópica. Portanto, este estudo tem como objetivo analisar e espacializar as ocorrências de incêndio em vegetação que estavam em contato a outros materiais combustíveis com a cobertura e uso da terra.

\section{MATERIAL E MÉTODOS}

A área de estudo foi no município de Curitiba, localizado no estado do Paraná, na região sul do Brasil, correspondendo às coordenadas de $25^{\circ} 25^{\prime} 41^{\prime \prime}$ de latitude sul e $49^{\circ} 16^{\prime} 23^{\prime \prime}$ de longitude oeste no seu marco zero, compreendendo uma área de 435,036 km² (INSTITUTO BRASILEIRO DE GEOGRAFIA E ESTATÍSTICA - IBGE, 2016). De acordo com Maack (2012) o município está inserido no bioma da Mata Atlântica, na região fitogeográfica limítrofe de campo com floresta ombrófila mista, apresentando uma área verde de 18.982,61 ha de acordo com estudo realizado por Monteiro (2015).

De acordo com os dados do Instituto Nacional de Meteorologia - INMET (2016), o município de Curitiba apresentou uma precipitação média anual de $1.706,5 \mathrm{~mm}$ e uma umidade relativa do ar média anual de $80,6 \%$ no período de 2011 a 2015. 
A coleta de dados foi mediante uma análise das ocorrências classificadas como "incêndio ambiental" atendidas pelo Corpo de Bombeiros da Polícia Militar do Paraná no município de Curitiba entre os anos de 2011 e 2015, disponibilizadas no Sistema de Registro e Estatística de Ocorrências (SYSBM-CCB, 2016).

Foi realizado uma consistência dos dados mediante leitura individual das ocorrências registradas no período analisado, verificando as que apresentavam características de incêndios em vegetação e as que se referiam a outros tipos de incêndio.

Após verificar as ocorrências que se enquadravam como incêndios em vegetação e contabilizadas para o período em análise, foi verificado quais possuíam relação com incêndios em outros materiais combustíveis durante o atendimento da ocorrência, como por exemplo em pneus, resíduos industriais, resíduos domésticos, entre outros.

Objetivando uma espacialização dos dados, foram obtidas as coordenadas geográficas das ocorrência que apresentavam uma localização exata em seu descritivo e estas posteriormente relacionadas com o mapa de monitoramento de cobertura e uso da terra do Brasil de 2016, disponibilizado pelo IBGE (2018), visando verificar se o local da ocorrência do evento apresenta relação com a influência antrópica ao eliminar resíduos materiais em geral. O mapeamento disponibilizado pelo IBGE (2018) apresenta 12 classes distintas para o território brasileiro conforme a Tabela 1.

Tabela 1. Classe de cobertura e uso da terra.

\begin{tabular}{ll}
\hline \multicolumn{2}{c}{ Classes de cobertura e uso da terra } \\
\hline Área artificial & Corpo d'água costeira \\
Área agrícola & Corpo d'água continental \\
\hline Pastagem com manejo & Vegetação campestre \\
Mosaico de ocupações em & Mosaico de ocupações em \\
área florestal & área campestre \\
Silvicultura & Área úmida \\
\hline Vegetação florestal & Área descoberta \\
\hline Fonte: adaptado de IBGE (2018).
\end{tabular}

Utilizando o software ArcGis (versão 10.6.1), foram inseridas as coordenadas geográficas das ocorrências e verificado em qual classe de cobertura e uso da terra estava localizada.

\section{RESULTADOS E DISCUSSÃO}

O Corpo de Bombeiros atendeu 2.229 ocorrências com a classificação "incêndio ambiental”, porém 1.255 ocorrências (56,3\% do total) foram classificadas como incêndio em vegetação. Destas, 108 ocorrências (8,6\%) apresentaram queima de outros materiais (pneus, lixo doméstico, lixo industrial, entre outros) além de vegetação. A Figura 1 apresenta a distribuição das ocorrências de incêndio em vegetação ao longo do período analisado e a Figura 2 apresenta as ocorrências de incêndio em vegetação em conjunto com outros tipos de materiais no mesmo período.

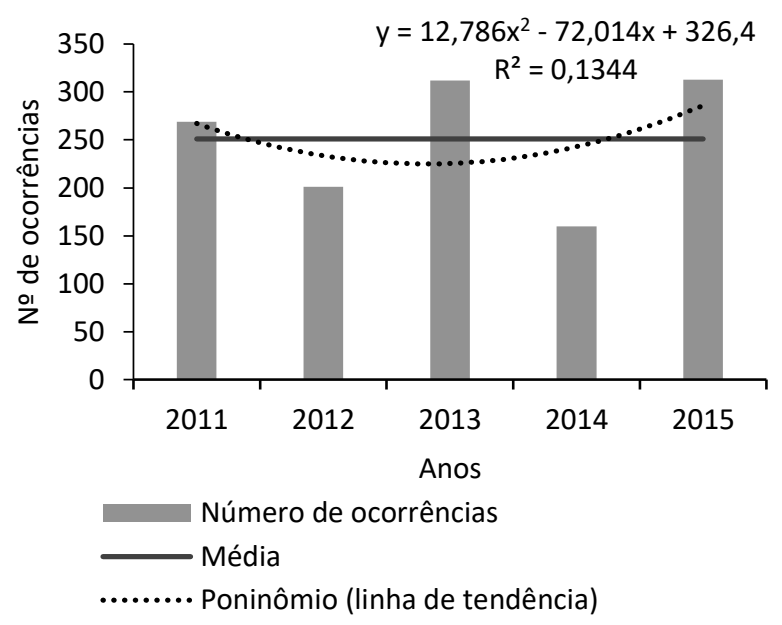

Figura 1. Distribuição das ocorrências de incêndio em vegetação ao longo do período analisado.

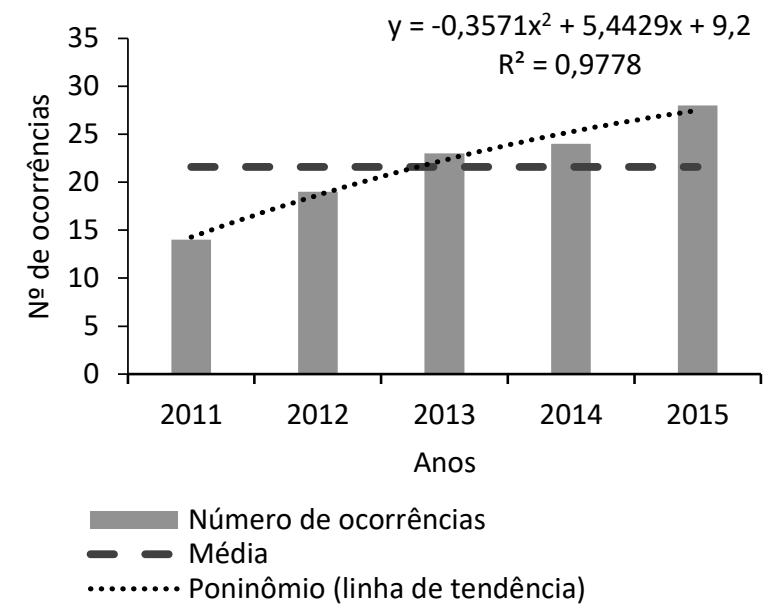

Figura 2. Distribuição das ocorrências de incêndio em vegetação em conjunto com outros materiais ao longo do período analisado.

Observa-se que o aumento de incêndios em vegetação relacionados com outros materiais foi crescente ao longo do período analisado, apresentando uma linha de tendência ascendente e ápice no ano de 2015 com 28 ocorrências, um aumento de mais de $100 \%$ se comparado ao ano de 2011 que apresentou 11 ocorrências. Esse 
aumento anual não foi verificado ao distribuir os incêndios em vegetação (com ou sem presença de outros materiais combustíveis) nos anos de 2011 a 2015 no município de Curitiba, que apresentaram maior número de ocorrências em 2015 e 2013 (313 e 312 ocorrências, respectivamente) e um menor número nos anos de 2011 (269 ocorrências), 2012 (201 ocorrências) e 2014 (160 ocorrências).

Ainda, Ferreira et al. (2017) verificaram que o ano de 2015 apresentou maiores médias de precipitação e umidade relativa no período analisado, indo ao desencontro do que normalmente favorece a ocorrência de um incêndio em vegetação: baixas umidades relativas e precipitações, visto que propicia ao material vegetativo uma característica mais seca, auxiliando na combustão. Assim, as vegetações presentes em áreas em conjunto com outros materiais apresentaram ao longo do ano uma menor tendência da ocorrência de incêndio, o que não se refletiu nos resultados obtidos.

O crescimento de ocorrências envolvendo a queima de outros materiais além de vegetação pode estar relacionado com a expansão das zonas urbanas e com a projeção do salto populacional de 1.786 .840 habitantes em 2010 para 1.912.757 habitantes em 2020, apresentando um crescimento de 7,05\% de acordo com o Instituto Paranaense de Desenvolvimento Econômico e Social (IPARDES) (2018), carecendo, no entanto, de um horizonte de tempo maior de avaliação das ocorrências para verificação dessa possível relação.

A Figura 3 apresenta a distribuição das ocorrências de incêndio em vegetação e outros materiais em Curitiba, ao longo do período analisado.

Pode-se verificar que Curitiba apresentou seis classificações de uso do solo: área artificial (66,6\%), mosaico de ocupações em área florestal (22,1\%), mosaico de ocupações em área campestre $(8,0 \%)$, vegetação florestal (1,2\%), corpo d'água continental (1,2\%) e vegetação campestre $(0,9 \%)$.

Ao distribuir as ocorrências de incêndio em vegetação misturada com outros materiais, verificou-se que das 108 ocorrências existentes, 12 não apresentaram uma localização exata, sendo assim descartadas para esta análise. Do total de 96 ocorrências distribuídas, 91 destas $(94,8 \%)$ estavam presentes em área artificial, quatro em mosaico de ocupações em área florestal (4,2\%) e uma em mosaico de ocupações em área campestre $(1,0 \%)$.

A área artificial é caracterizada por áreas com predominância de superfícies antrópicas não-agrícolas (IBGE, 2018), evidenciando-se assim que os incêndios em vegetação misturado com outros materiais estão ligados à presença antrópica. Não há como mensurar se a queima de outros materiais teve início antes da queima da vegetação ou vice-versa, porém a alta distribuição das ocorrências em superfícies antrópicas evidencia a relação das práticas de queima de outros materiais como possível causa para propagação de incêndios em vegetação.

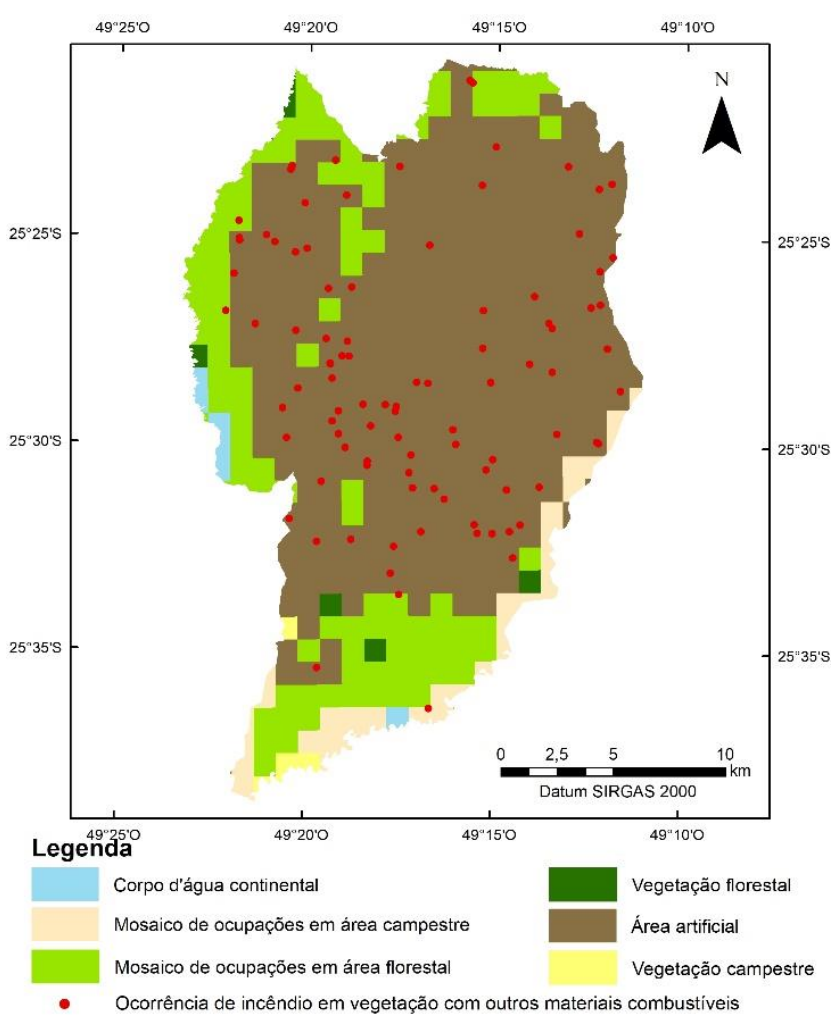

Figura 3. Distribuição das ocorrências de incêndio em vegetação em conjunto com outros materiais junto ao mapa de uso do solo de Curitiba.

Fonte: adaptado de IBGE (2018).

Para embasar a hipótese da influência antrópica na propagação dos incêndios em Curitiba, outros trabalhos como de Torres (2010) verificou influência antrópica devido ao alto número de incêndios em lotes vagos em Juiz de Fora, Minas Gerais e de Bonfim (2003) constatou que $73,4 \%$ dos casos dos incêndios no entrono do Parque Estadual da Serra do Brigadeiro, MG, tiveram como causa queimadas e atividades criminosas.

Dentre os principais motivos do início dos incêndios, pode estar atrelado aos resultados encontrados por Soares \& Santos (2002) e Santos et al. (2006) que verificaram que ao se tratar dos incêndios no Brasil, respectivamente de 1994 a 1997 e de 1998 a 2002, as principais causas foram de incendiários e de queima para limpeza.

Ainda, outros trabalhos como de Vosgerau et al. (2006), Soares \& Cordeiro (1974) e Tetto (2012) verificaram a influência antrópica na ocorrência de incêndios. Vosgerau et al. (2006) constataram em sua área de estudo que os 
fumantes foram os principais causadores de incêndios, porém essa informação provém de uma percepção das pessoas que se envolveram no combate às chamas, não sendo realizado uma investigação detalhada para confirmar de fato a causa. Soares \& Cordeiro (1974) verificaram que no município de Telêmaco Borba, Paraná, nos anos de 1965 a 1974, a maior causa de incêndios foram as queimas para limpeza. Tetto (2012) constatou que os incendiários foram os principais causadores de incêndios florestais na fazenda Monte Alegre, localizada em Telêmaco Borba, entre os anos de 1965 a 2009.

Criar políticas públicas bem consolidadas sobre o uso e a proibição do uso do fogo, é uma maneira de mitigar os efeitos e reduzir as ocorrências de incêndios antrópicos. Para tanto, o município de Curitiba, por meio da Lei $\mathrm{N}^{\circ}$ 14.342 (CURITIBA, 2013), proíbe a queima de resíduo domiciliar, mato ou qualquer outro material orgânico ou inorgânico. No entanto, sugere-se a causa antrópica como a principal responsável pelos incêndios em vegetação no município um indicativo de que a legislação por si só é ineficaz, sendo necessária a implantação de campanhas educacionais e instrução à população.

\section{CONCLUSÕES}

Com base nos resultados obtidos verifica-se que houve um aumento crescente do número de ocorrências envolvendo incêndio em vegetação e queima de outros materiais, no período analisado. Recomenda-se uma avaliação dos anos subsequentes para verificar se há um crescimento destas ocorrências.

Ainda, observam-se indícios de que os incêndios em vegetação em conjunto com outros materiais combustíveis possuem relação causal antrópica que pode estar associado a utilização do fogo para eliminação de resíduos em geral, mas é necessário um aprofundamento de pesquisas junto à população acerca da utilização do fogo para eliminação de resíduos.

\section{REFERÊNCIAS}

ASSUNÇÃO, R. et al. O uso tradicional do fogo no assentamento Vale Verde, em Gurupi/TO. Revista Espacios, v.38, n.17, p.1-19, 2017.

BONFIM, V.R. et al. Diagnóstico do uso do fogo no entorno do Parque Estadual da Serra do Brigadeiro (PESB), MG. Revista Árvore, v.27, n.1, p.87-94, 2003.

BOWMAN, D.M.J.S. et al. The human dimension of fire regimes on Earth. Journal of Biogeography, v.38, p.2223-2236, 2011.

CHANDLER, C. et al. Fire in forestry. Volume II - Forest fire management and organization. Canada: John Wiley \& Sons, 1983.

CURITIBA. Lei no 14.342, de 05 de novembro de 2013. Diário Oficial Municipal, Curitiba, 2013. Disponível em: https://leismunicipais.com.br/a/pr/c/curitiba/lei-ordinaria/2013 /1434/14342/lei-ordinaria-n-14342-2013-

FERREIRA, H.R. et al. Análise das ocorrências de incêndios em vegetação, no período de 2011 a 2015, no município de Curitiba, Paraná. Investigaciones de pregrado sobre manejo del fuego. Guayaquil-Equador: Grupo Compás, 2018.

HEIKKILÄ, T.V. et al. Wildland fire management: handbook for trainers. Helsinki: Kirjapaino Topnova Oy, 2007.

IBGE - INSTITUTO BRASILEIRO DE GEOGRAFIA E ESTATÍSTICA, 2016. Disponível em: http://cidades.ibge.gov.br/xtras/ perfil.php?codmun $=410690$

IBGE - INSTITUTO BRASILEIRO DE GEOGRAFIA E ESTATÍSTICA. Monitoramento da cobertura e uso da terra do Brasil (2014 2016). Rio de Janeiro, 2018.

IPARDES - INSTITUTO PARANAENSE DE DESENVOLVIMENTO ECONÔMICO E SOCIAL. Projeção da população dos municípios do Paraná para o período 2018 a 2040. Curitiba, 2018.

INMET - INSTITUTO NACIONAL DE METEOROLOGIA, 2016. Banco de dados meteorológicos para ensino e pesquisa (BDMEP), 2011 - 2015. Disponível em: http://www.inmet.gov.br/projetos/rede/ pesquisa/

LIU, Z.; WIMBERLY, M.C. Climatic and landscape influences on fire regimes from 1984 to 2010 in the western United States. Plos One, v.10, n.10, e0140839, 2014.

MAACK, R. Geografia física do estado do Paraná. 4.ed. Ponta Grossa: Editora UEPG, 2012.

MOLINA, D.M. et al. Incendios forestales: fundamentos, lecciones aprendidas y retos de futuro. Espanha: AIFEMA, 2009.

MONTEIRO, M.M.G. Caracterização da floresta urbana de Curitiba-PR por meio de sensoriamento remoto de alta resolução espacial. 2015. 147p. (Tese de doutorado).

PARANÁ - Assembleia Legislativa do Estado do Paraná Constituição do estado do Paraná. Curitiba, 1989. Disponível em: http://www.assembleia.pr.leg.br/legislacao/constituicaoestadual

PRUDENTE, L.T. O lugar da interface rural-urbana no planejamento territorial: estudo de caso da região metropolitana de Porto Alegre/RS. $1^{\circ}$ Congresso brasileiro de geografia política, geopolítica e gestão territorial, p.1258-1269, 2014.

ROSAS, C.A.R.F. As interfaces da relação rural-urbano no Brasil: notas para debate. Terra Plural, v.8, n.1, p.165-184, 2014.

SANTOS, J.F. et al. Evolução do perfil dos incêndios florestais em áreas protegidas no Brasil, de 1993 a 2002. Floresta, v.36, n.1, p.93-100, 2006. 
SOARES, R.V. et al. Incêndios florestais: controle, efeitos e uso do fogo. 2.ed. revisada. Curitiba, 2017.

SOARES, R.V.; CORDEIRO, L. Análise das causas e épocas de incêndios florestais na região centro- paranaense. Floresta, v.5, n.1, p.46-49, 1974.

SOARES, R.V.; SANTOS, J. F. Perfil dos incêndios florestais no Brasil de 1994 a 1997. Floresta, v.32, n.2, p.219-232, 2002.

SYSBM-CCB. Cascavel: Corpo de Bombeiros. 2011-2015. Disponível em: http://www.bombeiroscascavel.com.br/ registroccb/

TETTO, A.F. Comportamento histórico dos incêndios florestais na Fazenda Monte Alegre no período de 1965 a 2009. 2012. 114p. (Tese de doutorado).

TORRES, F.T.P. et al. Determinação do período mais propício de incêndios em vegetação na área urbana de Juiz de Fora, MG. Revista Árvore, v.34, n.2, p.297-303, 2010.

VÉLEZ, R. La defensa contra incêndios forestales: fundamentos y experiencias. 2.ed. Madrid: McGraw-Hill, 2009.

VOSGERAU, J.L. et al. Avaliação dos registros de incêndios florestais no Estado do Paraná no período de 1991 a 2001. Floresta, v.36, n.1, p.23-32, 2006.

Recebido em 04-07-2019 Aceito em 18-10-2019 